\title{
iPads in Education? A Participatory Design for Professional Learning with Mobile Technologies
}

\author{
Keith Turvey \\ Education Research Centre, School of Education, University of Brighton, UK \\ k. turvey@brighton.ac.uk
}

\begin{abstract}
It is recognised in the literature that mobile technologies have the potential to 'disrupt' established practices in ways that require adaptation if educators are to harness their potential. Thus, there is a need for participatory models of research and partnership that give teachers agency over the process of professional development with new technologies at a time when there is increasing pressure for educators to respond to the proliferation of mobile technologies. This paper reports on the development and initial testing of a participatory narrative ecology approach to developing teachers' professional practice with mobile technologies in the UK. A prototype, haptic infographic was developed that teachers and teacher educators could use to story the development of their pedagogical practice as they appropriated mobile technologies in various contexts. The narrative ecology model was developed through a participatory methodology of working with school and university partners in teacher education. The objective was, to explore the model as a participatory approach to developing educators' critical analysis of the process of appropriating mobile technologies for educational purposes and, to capture the subsequent process of pedagogical adaptation. This paper focuses in detail on both the narrative ecology model and how it was used in the case of a secondary school science teacher. The emerging evidence suggests that the process of adaptation to mobile technologies in education is prolonged and complex. Yet in a digital age of rapidly increasing connectivity and converging cultures there is a need for further research into the implications of mobile technologies and how educators can be located as central agents in changing and adapting pedagogical practices. The findings also suggest that participatory narrative approaches offer potential for exploring new designs for pedagogical practice with mobile technologies.
\end{abstract}

Keywords: Pedagogy, narrative methods, didactic analysis, participatory design, mobile technologies.

\section{Introduction}

The project was designed to test and develop a model of narrative ecology in educators' professional practice with mobile technologies. A prototype infographic for iPad was designed that teachers manipulate through gestures and use as a prompt for articulating their pedagogical narrative concerning their appropriation of mobile technologies into their practice (Figure 1). 


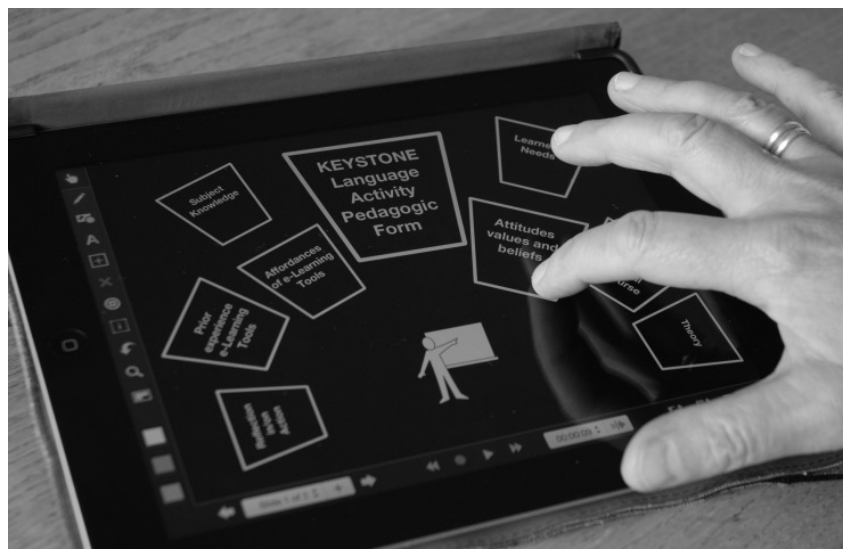

Fig. 1. Narrative ecology iPad infographic - blocks are manipulated (resized and moved) to prompt discussion

The resource was developed and introduced through a participatory model of working with school and university partners in teacher education. The overall objective of the project was to find out how effective the narrative ecology model (Turvey, 2013 [1]) can be in developing educators' critical analysis of the process of appropriating mobile technologies for educational purposes. This is important because I argue there is a need for participatory models of research and partnership in teacher education and development that give teachers agency over the process of professional development with new technologies at a time when there is increasing pressure for educators to respond to the proliferation of mobile technologies and the convergence of social and professional networking practices (Pachler, Bachmair and Cook, 2010 [2]; Turvey, 2012b [3]). The project was also significant in enabling the partnership schools and the School of Education at the University of Brighton to take advantage of the new relationships that are emerging between $\mathrm{HE}$ and schools in response recent teacher education reforms in England. The main aims of the project were:

- To form new models for working with partners through participatory research into professional practice, pedagogy and mobile technologies;

- To investigate a narrative ecology framework as a model for critical reflection and development in the appropriation of new technologies in educators' professional practice;

- To develop a prototype interactive iPad resource (Figure 1) to support educators' professional and critical judgements of the integration of mobile technologies in education through dialogue and narrative.

Teachers from three partnership schools were engaged in the project. Their secondary schools (11-16 year olds) had recently launched 1:1 iPad initiatives to support learning and teaching. Similarly, the School of Education, University of Brighton had embarked on a mobile learning project with a number of lecturers in initial teacher education exploring the use of iPads in their professional practice in response to recent higher education policy reports (HEFCE, 2009 [4]; JISC, 2009 [5]). 
Thus, the project was timely and provided an opportunity to work with local partners investigating professional practice in the context of newly acquired mobile technologies (iPads). Initial meetings held with representatives from the schools identified a common need to examine how the iPads can be harnessed to support teachers' professional and pedagogical development, and ultimately enrich the learning experiences of students. Thus, the aims of this project were designed around a participatory model of research that could generate empirical evidence, in the form of narrative cases, of the process of mobile technology (iPads) appropriation in educational contexts.

\section{Discussion and Literature}

It is recognised in the literature that mobile technologies have the potential to 'disrupt' established practices in ways that require adaptation if educators are to harness their potential (Jenkins, 2006 [6]; Baron, 2008 [7]; Pachler, 2009 [8]; Traxler, 2007 [9] \& 2010 [10]). A more detailed depiction of the character of such 'disruption' is emerging with research focusing variously on concepts of convergence, mobile learning, personalisation, connectivity, sustainability and indeed the compatibility of emergent mobile learning practices within established contexts of formal education (Traxler, 2010 [10]; Pachler, Bachmair and Cook, 2010 [2]; Crook, 2012 [11]). The emerging evidence suggests that the process of adaptation is prolonged and complex. Yet in a digital age of rapidly increasing connectivity and converging cultures there is a need for further research into the implications of mobile technologies and how educators can be located as central agents in changing and adapting pedagogical practices. The discourses at the interface of macro-level educational policy and the micro-level contexts of professional practice are fertile ground for understanding the complex and unpredictable process of technological appropriation and its implications for education (Castells, Fernadez-Ardevol, Linchuan Qui and Sey, 2007 [12]; Pachler et Ranieri, Manca and Cook, 2012 [13]; Selwyn, 2012 [14]). Processes of technology appropriation are often far less transformative of pedagogical practice in the short term than techno-centric arguments proclaim (Cuban, 2001 [15]; Selwyn, 2012 [14]; Crook, 2012 [11]). However, Jenkins (2008, p.11 [6]) has argued that we are in a 'period of prolonged transition' with regards the implications for new technologies and the way we learn. Similarly, Laurillard (2012, p. 226 [16]) comments 'the difference that marks out the early years of the twenty-first century from any previous period in education is that digital technologies not only enable a change to treating teaching as a design science, they also require it.' Hence, the narrative ecology framework uses participatory narrative methods to place teachers at the centre of this process of teaching as a process of design. In any such pedagogical design process teachers are conceived as active agents (Somekh, 2007 [17]; Pachler, Cook and Bachmair, 2010 [18]).

The narrative ecology model of technological appropriation I will posit for discussion here places the appropriation of mobile technologies within their wider educational and socio-cultural contexts emerging as it does from critique of Activity 
Theory (Engeström, 1987 [19], 2000 [20], 2001 [21]) that questions the place of intentionality and individual agency within Activity Theory (Nardi, 1996 [22]; Wertsch, 1998 [23]; Ellis, Edwards and Smagorinsky, 2010 [24]). That is, in the narrative ecology model, digital technologies are not merely conceived of as educational tools mediated by educational and wider socio-cultural contexts, but also as integral items of the expressive life and intentionality of the individual (Goffman, 1959 [25]; Perkins, 1993 [26]); that is, for effective appropriation to occur I argue that technologies need to be conceived as an anthropomorphic extension of teachers' multiple identities within contemporary society. Technology brings I suggest an added layer of complexity and potential disruption to the established professional and socio-cultural ecology of the classroom and is inherently problematic (Turvey and Pachler, Forthcoming [27]). As long as techno-centric arguments dominate this discourse I argue that at best technology will continue to disappoint in terms of realising anything more than a perfunctory role in education and at worst may bring further disruptive unintended consequences.

\subsection{The Narrative Ecology Framework}

The narrative ecology framework offers a process of participatory research into professional practice with new technologies (Turvey, 2012a [3], 2012b [28], and 2013 [1]). This model is positioned within a significant body of research focusing on teachers' innovation with new technologies (See for example Fisher et al 2006 [29]; Somekh, 2007 [17]; Loveless, 2003 [30] and 2007 [31]). As such it places teachers at the centre of the pedagogical design process with new technologies and offers a useful tool for the synthesis and analysis of technological tools and pedagogical processes. It is an attempt to recognise Klafki's (1995/1958, p.21 [32]) didactic analysis of pedagogy 'as a selection made in a particular human, historical situation and with specific groups of children in mind' but which can also illuminate the macro-to-micro and micro-to-macro imperatives and constraints at play as teachers appropriate technologies into their practice. It is a theoretical tool for developing more rich, "stateof-the-actual' descriptions of technology-enhanced learning (Selwyn and Facer, 2013 [33]). As Loveless and Williams state (2013, p.158 [34]); 'being ready, willing and able to teach, calls for a reading of the world in which content, context and tools can be orchestrated with skill and purpose.' The German tradition (Klafki, 1995/1958, p.20 [32]) of didactic analysis requires the teacher not just to understand the what (content) and the how (pedagogy) but also the why 'with its attendant past and the anticipated future'.

From these perspectives I argue that the pedagogical appropriation of new technologies is a complex process, predicated on the interdependency of various contextual and autobiographical factors. In the model, these are arranged in an arch structure supporting the concept of a pedagogical keystone (Figure 2). The variable factors identified are; the affordance of the technological tools; teachers' and learners' subject knowledge; learners' needs and teachers' perceptions of learners' needs; teachers' and learners' prior experience of the e-learning tools available; teachers' and learners' attitudes and values; teachers' capacity to reflect in or on action; wider 
socio-cultural discourse around policy, education and technology and; intrinsically or extrinsically generated theories of pedagogy and practice. These contextual and autobiographical factors are conceived as an ecology creating both resonance or dissonance in the development of the teacher's pedagogical keystone. A pedagogical keystone is defined here as the synchronic interdependency of the contextual and autobiographical factors at play as the teacher goes about their work of designing contingencies for learning. As Postman notes, (1993, p.18 [35]) in an ecological system, change in one variable 'generates total change' to the system as a whole. However, there can be a tendency to regard agents as passive actors settling into new niches as the ecology changes around them. On the contrary, Normak, Pata and Kaipainen (2012, p.264 [36]) define a niche as a 'learning onto-space' where the 'perceived qualities of persons' such as their past experiences and intentionality (autobiographical) are significant factors in the ecology in which they are operating.



Fig. 2. Narrative ecology theoretical framework

If as discussed earlier, we perceive of the pedagogical process as a design process, the qualities and intentions the teacher brings are vital and live elements within the ecology. A key issue, however, is how such past experiences and intentionality can be captured as they are woven into the teacher's interactions within a dynamic and complex pedagogical ecology incorporating mobile technologies. In the narrative ecology model this complex and dynamic interdependency between the tools, the context and the agent's intentionality and experience is represented through the concept of a pedagogical keystone (Figure 2). Narrative, with its potential to reveal 
participants' underlying 'organising principles' (Goodson, 2008, p.18 [37]) as they act on the world, is seen as an important methodological device in capturing and characterising the teacher's pedagogical keystone. Narrative methodologies have the potential as Schostak discusses to position subjects as 'expert in their own ways of seeing,' (2006, p.149 [38]). Furthermore, as Pata (2011, p.3 [39]) notes, narratives are useful 'vehicle[s] for meaning making and identity-determination.' That is, narratives can bring deeper meaning to the apparently isolated yet constituent events and activities as they can convey "what one thinks one did in what settings in what ways and for what felt reasons' (Bruner, 1990, p.119 [40]). Such narrative methods require establishment of trusting and participatory relationships between research participants and researcher so the conduct of the project was important as I discuss now.

\section{Conduct}

This project was conducted in two phases (Table 1). In phase 1, a day symposium was held at which secondary school teachers and lecturers in initial teacher education were invited to present to colleagues about how they were incorporating the use of iPads into their professional practice. These presentations were video recorded with the permission of participants. At the symposium, the narrative ecology model was also presented to participants and a group discussion was held which was also recorded. The participants were given access to the recordings of the presentations, group discussion and the editable infographic of the model (Figure 1) on their own iPads for use in phase 2 of the project.

During phase 2 a self-selecting sample of 4 participants 2 secondary school teachers and 2 lecturers in initial teacher education agreed to further participation. An in-depth narrative interview was conducted with these participants in which they were supported in using the framework to narrate and discuss their on-going experiences of incorporating the iPads in their professional practice.

Table 1. Methods and data collection

\begin{tabular}{cll}
\hline Project Phase & Type of data & Quantity \\
\hline 1 & Group Interview & 8 Participants \\
& Presentations & \\
& Field notes & 4 Participants \\
\hline 2 & In-depth narrative interviews & \\
& Narrative portrayals & \\
& Participant response and commentary \\
& on narrative portrayal & \\
& Documentary evidence (e.g. \\
& published material by schools about \\
& their 1:1 iPad projects) & \\
\hline
\end{tabular}

These individual narrative interviews together with the participant's presentation, their contribution to the group discussion from the symposium and any further 
documentary evidence were then analysed using Nvivo. The 8 variable factors identified in the narrative ecology framework (Figure 2) were applied to the qualitative data. As far as possible the raw data was used for analysis as opposed to transcribing the video and audio footage. That is, footage was coded using the 8 variables from the model directly in Nvivo. This enabled more direct engagement with the raw data and was felt to add to the validity of the interpretations being made as important aspects such as tone remained integral to the raw data. Figure 3 illustrates this process showing the coding applied to one of the in-depth narrative interviews.

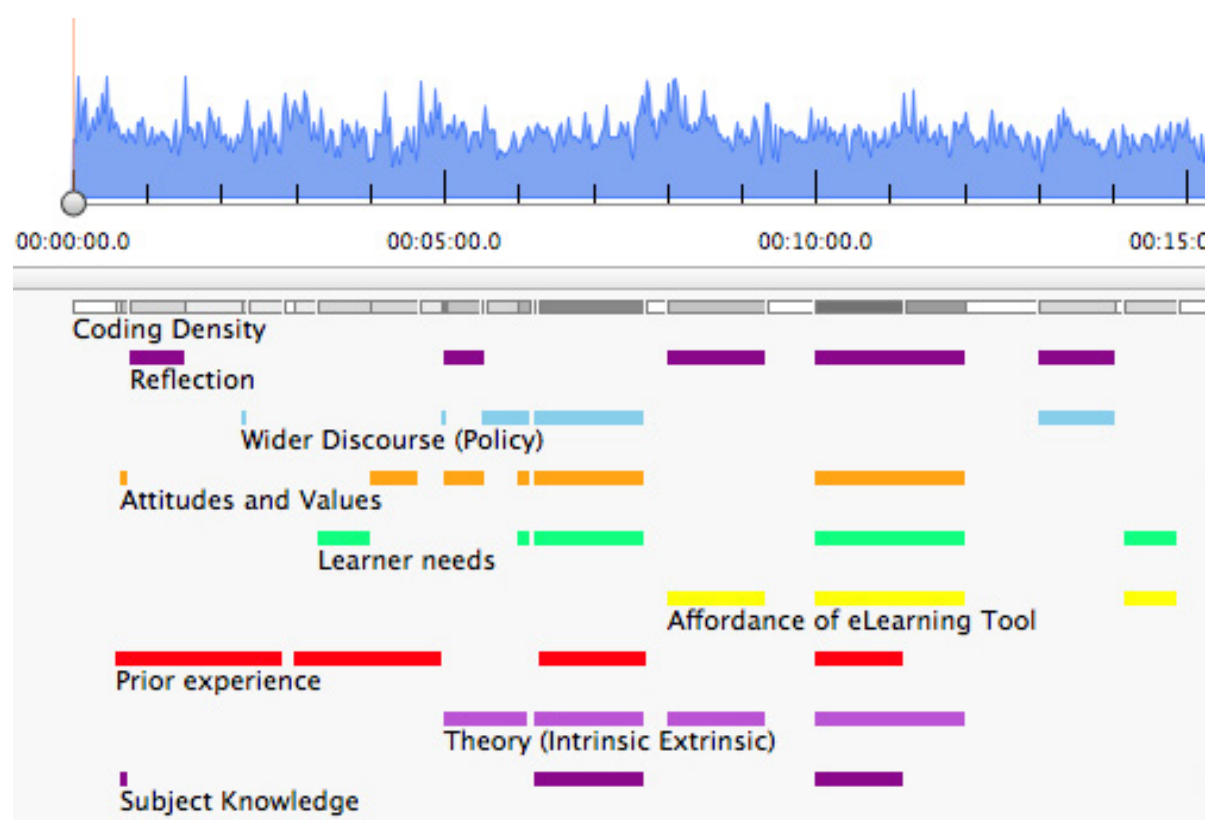

Fig. 3. Narrative ecology coding applied to in-depth interview using Nvivo

When the data had been analysed and coded, an individual narrative summary was constructed. The narrative summary was an attempt to identify from the data, the individual participant's pedagogical keystone or the factors which appeared to take priority and have most influence as they reflected on their appropriation of the mobile technologies into their pedagogical practice. The narrative summary was then shared with the participant for further commentary on the researcher's interpretation and further reflection.

It is acknowledged that this approach does not easily lend itself to broad generalisations about the impact of technologies in education. The aim of the research was to understand and capture in much more depth, the complex qualitative ways in which educators adapt their pedagogical practice when incorporating mobile technologies and what factors appear to guide and influence this. As Crook et al. (2010, p. 53 [41]) note, the 'impact' of new technologies in education is often defined narrowly in terms of examination results and attainment whereas 'the value added 
may be more than the value measured'. It is argued here too that any narrowly defined impacts of technologies in education are largely meaningless and open to questioning without the rich qualitative factors that characterise dynamic educational contexts and educator experiences. It is beyond the scope of this paper to present and analyse all of the participants' narrative cases. I will therefore focus on the presentation and analysis of one case in depth.

\section{Narrative Case: Sam}

Sam is a Science teacher in a large secondary school in England (11-16 year olds). At the time of this research she was in her seventh year as a qualified teacher and as well as her role in the science department she had a role as a 'digital leader', providing support to other colleagues with the integration of digital technologies into their pedagogical practice. The school has recently adopted a 1:1 iPad policy providing all students with iPads through a scheme in which parents can purchase an iPad for their child at various subsidised levels depending on financial circumstances. There are also options provided for those families just above the Free School Meal entitlement threshold who are unable to afford to buy a device. The school looked into various strategies such as Bring Your Own Device (BYOD) before adopting their approach and Sam was involved in this process from early on. So as a 'digital leader', significantly involved in the 1:1 iPad project she has already identified herself as open to the aims of this school-wide initiative which were identified as:

- Empower students by encouraging creativity, problem-solving and independence in their learning;

- Provide an increasingly high degree of personalised feedback to students and their families;

- Bring students into closer partnership with teachers in the development of learning pathways and learning materials;

- Systematically share learning materials with students and parents in order to empower their support for learning anytime, anywhere;

- Place our teachers at the heart of a vibrant local and national innovation partnership where skills, knowledge and learning materials are actively shared and developed. ${ }^{1}$

In this narrative portrayal of Sam's current position with regards the wider school iPad initiative and her own professional practice I identify three significant themes that emerged from my analysis of Sam's narrative ecology, namely; prior experience, attitudes and values, recognition of learner needs and agency. These themes overlapped throughout the analysis of the data and also appeared to reveal an underlying open yet pragmatic approach to pedagogical adaptation, as Sam continues to reflect on the implications of the 1:1 iPad initiative for her own pedagogical practice. As might be expected when researching the professional practices and perceptions of experienced teachers such as Sam, the variable themes identified within the narrative ecology framework were often densely populated in the data in

1 Documentary evidence provided by the school in the public domain. 
Sam's case. For example 51.7\% (Nvivo) of the source data was coded against the theme of reflection indicating the extent of her capacity to critically reflect on the initiative in question. However, while this capacity to reflect critically was no doubt significant in Sam's case it is the nature of the insights afforded by these reflections that led to the glimpses of Sam's open yet pragmatic approach to pedagogical adaptation in response to the 1:1 iPad initiative in her school. This open yet pragmatic approach revealed itself in the interplay between her prior experiences, her attitudes and values and the ways in which she appeared to adapt her pedagogical practices in ways that were sensitive to learner agency and needs as I will explore now.

\subsection{Prior Experience; Attitudes and Values; Learner Agency and Needs}

These three themes were often present in the data as was apparent from Sam's initial reflections in the interview when I asked her to tell some of her background and route into the teaching profession. She related that as part of her degree in Human Sciences, which she describes as a course that tried 'to bridge the divide between the arts and science,' she had been prompted to reflect on her development and through this process she states that:

'I realised at the end of the degree that I did want to do something to do with education. It had become really obvious to me that what I cared about was how do you get students to really understand and how do they become part of that? How do you make it happen basically?'

That is, helping students to 'become part of' the learning process or active agents in the process of learning was identified as being important to her on first thoughts of entry to the profession. Another important factor of her prior experience and route into the profession was her work as a learning mentor supporting children with Special Educational Needs (SEN) which she believes continues to influence her approach now as a teacher. For example she related:

'I would say that influences my teaching quite a lot because I've come from that background of SEN. I wouldn't say that makes me any better than anyone else at dealing with that, but awareness side of things ...... I find that experience helps me when building good relationships with students.'

Sam places emphasis on the importance of teachers having 'good relationships' with students here again signposting this aspect of her attitudes and values about teaching and learning in terms of learners' needs but also locating this in her prior experiences as a learning mentor. As Sam began to talk more about her practice, however, she was keen to point out that she was also quite pragmatic in her approach to her pedagogical practice. This was evident when prompted to try and describe what kind of teacher she felt she was as she replied 
I think I kind of go from one extreme to the other from being quite didactic this is what we need to learn about and I can't think of an exciting way to do it or teach it (laughing). I'm just going to tell you (in a teacher voice)... to the more extreme I going to think of something ridiculously creative and I'm going to get you on board.....I guess as a teacher I go from one to the other. I don't always necessarily get them as tied together...'

That is, she sees her teacher identity as a synthesis of these two extremes, the ideal being when she is able to combine aspects of creative teaching which actively engages her students with more authoritative and didactic approaches. Furthermore she offers more evidence that this open yet pragmatic pedagogy she is developing lies in her prior experiences by referring back to her experiences as an Aim Higher learning mentor as she continues:

'I don't want to sound too idealistic or have ridiculous ideas like a PGCE student just coming into it. But I've come into it because of my background as a learning mentor. As an Aim Higher learning mentor the whole purpose was to get children into higher education who might not have thought it was a possibility for them. And the students I was working with in my first place as a learning mentor were on the $C / D$ borderline. So things that were happening in a lesson where they could have understood if you'd just used the right example or just made it applicable in some way to them. It was what the teacher did that could have made a massive difference and I think it's this that made me realise I wanted to be a teacher rather than a learning mentor. The reason I came into teaching is because I saw that...it's like an inequality of access to learning and understanding. And that need to try and address that balance and make it more equal. But they're kind of pie in the sky idealisms that don't necessarily play out day to day.'

The ambiguity in her first sentence is interesting in that Sam is positioning herself as open to innovation and ideals but at pains not to appear naïve. As an experienced practitioner she appears to hold onto certain ideals about the needs of learners and helping them to access knowledge and understanding. The last sentence of this extract clarifies that despite holding such ideals, she recognises them as ideals that are often problematic to realise in practice.

These interview extracts suggest that the way Sam currently positions her professional practice, including her attitudes and values about teaching and learning, together with her perceptions about learners' needs, are located in both her current and prior experiences in becoming a teacher. These themes can be seen as significant nodes within her narrative ecology, which continue to resonate in her on-going narrative of professional identity formation. Furthermore these themes remain significant as Sam relates her on-going experiences of adapting her pedagogy with the introduction of the iPads. 


\subsection{Pedagogical Adaptation}

The ways in which the 1:1 iPad project had begun to impact upon and become appropriated by Sam, and to some extent some of her colleagues in the science department was evidenced through her presentation and contribution to the mobile learning symposium that was held at the University, but also through the school-based interview and observation. During the symposium, after explaining the background information of her school's 1:1 iPad initiative, she went on to share how as a science department they were exploring the use of the iPads in learning and teaching. There appeared to be an early progression in that initially the focus was very much on finding particular apps for specific science topics in order to illustrate difficult concepts. However, Sam went on to say that 'in science one of the most powerful things has just been the camera.' She described how they had explored a range of uses of the iPads but much of this involved visual aspects such as taking microscopic photographs. Similarly, there had been much experimentation with creating short animations of scientific processes with one teacher using animation to model ionic bonding with the children. On my visit and observation I watched another teacher creating a short time-lapse animation of the process of crystallisation as hot wax cooled slowly on a microscope slide. The iPad was set up on an improvised rig to hold it steady over a period of time. However, it was during the interview with Sam that she offered more of an insight into her own interpretations of these pedagogical science initiatives and how her prior experience of her Human Sciences degree influenced this interpretation. For example when asked to describe her own practice with the iPads she relates:

'I don't know if we've got any further but I think it requires looking at things from a thinking skills perspective. We've done things like mapping apps to Blooms but I don't think that actually means anything...it's about what's the task not what's the app? So we're using animation a lot and that seems for science particularly a good way in to using iPads....... But if you just say to students OK here's a topic/process....and me as quite a visual person with a science background I can think of oh I would do this with it...I could do that with it...but students are not necessarily bringing that to it as they don't have that kind of experience or maybe their brain doesn't work that way. So we've had to structure the experience. And a more successful way of doing it seems to be where you give them a diagram and maybe some plasticine and they literally do the moving. So it's all there for them and they're just showing the process. So it's pinning down the real specifics.....(Pauses) I would quite like to see that built into students becoming more creative in their own way which is what I had with some Year 11s last year. These two girls who just got it. They had that visual and kind of design perspective on it and they really grasped what they could do with it, how it could look and really ran with it which I think students could get to but maybe it's a step-by-step thing which requires a longer term view, which I haven't really thought about yet.' 
What is particularly interesting about this response is that Sam appears to be recalling her own experiences of her Human Sciences degree, which she described earlier as trying to bring together the 'arts and science' and using this experience to consider how the affordances of the technology can be exploited more effectively in her teaching and the children's learning. In terms of the learners' needs she recognises that they may not have the visual literacy skills to be able to exploit the tools offered by the iPad to illustrate scientific concepts in new ways and therefore has adapted her practice to suit, limiting the resources she makes available to the children to ensure that they can focus on the scientific processes involved rather than becoming inhibited by their potential lack of visual literacy or being overwhelmed by the creative possibilities. Again it appears her approach can be characterised here as pragmatic openness as she is prepared to explore the potential of the tools but recognises the important role she can play in scaffolding the experience for the learners in order to avoid the students becoming more concerned with what she described as 'style over substance'. Furthermore, despite being pragmatic and thinking about how she can adapt her practice to scaffold the learning she sustains the ideal to which she sees herself working whereby children will be able to become more independent and creative in time as she goes on to express further:

'The idea is where they're doing the creation themselves of what they've learnt and presenting it for you and themselves as a coherent thing that they've worked out...that's when the penny drops and it's a much stronger experience but then that's where we're talking about the highest level skills and that's not necessarily where most students are going to get to in the course of a 100 minute lesson.....but yeh that's what it would be ideally.'

That is, she acknowledges that her current approach does not cede as much agency to the learners as it could, due to the constraints of time, the need to remain focused on the scientific subject knowledge and the possible limitation of children's visual literacy, yet she retains the ideal of the learner being able to take greater agency in the process of illustrating and demonstrating their learning and understanding. Again this demonstrates an openness to further pedagogical adaptation but from a pragmatic position. This sense of taking increased responsibility for one's learning is something again that appeared to be echoed in Sam's prior experiences. When prompted to reflect on her own experience of using technologies she recalls her experience growing up around technologies noting that:

'Yeh...I'm capable...I'm not any kind of expert with computers...erm..I was thinking about this the other day as I was talking to someone about having a Spectrum when we were young and I was thinking I need to ask my Mum and Dad you know why did they buy one.... It would have been quite expensive ... but they obviously saw this technology and thought wow we're going to get our children a computer and we ended up trying out programming and Basic and stuff... So we always had something and we had the Internet from about 1997 at home and I used to use.. (builds up suspense) Encarta 
(laughs..). But also we had reference books, encyclopaedias and things that I used to use and I'd go between the two. And you know I like...I've got a smartphone. And I use my computer quite a lot but I'm not an expert. I'm not massively technological... I'm quite practical so if I don't know how to use something I look it up and I find out and I work it out. So yeh generally... like I changed the hard drive on my laptop but you know...Google it...figure it out and have a go.'

Thus, Sam's attitudes and values regarding agency in learning as expressed in the desire to move closer towards a pedagogy that affords greater agency to learners is a pattern that can be traced in her own prior experience of using technologies in her willingness and capacity to 'figure it out and have a go'. The significance of this seemed also to resonate further. Learners taking responsibility for their learning and the decisions they make is one of the ways that Sam frames and resolves some of the day-to-day tensions that the introduction of iPads into the classroom has brought. Moreover, some of these tensions resonate beyond the classroom as Sam talked about how she assuages parents' concerns that the presence of the iPads might prove to be too much of a distraction from learning for their children, as she says:

'Like when I'm talking to parents I put it in this way ....like I say if we were in a meeting now, I have a choice and say there are lots of people in the room they have a choice...I could look at my emails but I'm not going to because I'm concentrating on what we're talking about.. I have that choice....There are plenty of adults who wouldn't be able to ignore that and think look I've got to do that now. And this technology is going to be there now forever and we need to help students to develop that ability to say "I'm going to ignore that" and help them to see that it's their responsibility.'

Hence she draws on her attitudes and values built from her own prior and current experiences that learners need to take responsibility for their own learning and the choices they make. Whilst Sam recognises there is a potential tension and disruption to learning as children could become distracted by the technology she is accepting of this tension recognising it as part of the learning process. Indeed, Sam provides yet further evidence of how she is adapting her pedagogy to the inclusion of iPads, using her attitudes and values about learning and agency as a guiding principle in an incident she related both in her presentation at the university-based symposium and her interview. She continues:

'I caught myself almost about to have a go at a student who....... had some like finger puppets (laughs) and we were talking about a tapir and I was like is it a tapir or is it an ant eater or is it an aadvark? And I was like hang on ant eaters and aadvarks I get confused (laughing)... which is which? We had a little discussion and no one quite knew so we were carrying on and I was talking about what they were going to do and one of them was on their iPad. I was thinking "oh no I'm going to have to have a go" and then I realised "oh no he's looking up...he's just finding out for me”. Ant eaters...aadvarks 
are they different?... "Yes they are here we are miss".... You have to allow a bit more freedom I think...You have to be willing to let go of the reins a little bit.'

Interestingly, although Sam is open and willing to 'allow a bit more freedom' in the pedagogical process she also appears to be pragmatic in adapting her pedagogy to accommodate this freedom yet retain control as she goes on to explain that 'I think I have relaxed a bit in that I think they're on their iPad but you know (pauses)..... look for clues.' The clues she now looks for are the gestures that the children are making as they interact with their iPads as she explain further:

'So today someone was doing this (gestures and acts like someone tilting their iPad) and I said (puts on teacher voice) "I don't think anything I've asked you to do today involves you needing to tip your iPad like that.." And you know it made them laugh because they knew they weren't doing the right thing. But you can sort of tell by gestures if they're doing something they are supposed to or not. But it is disconcerting because the teacher alarm goes off a lot more in my head than it used to. So as you're walking around the classroom, it might be that you've asked them to do something but you haven't stipulated whether it's on paper or iPad then there is that possibility but even if it is on paper....are they looking something up and referring back to it?..... So you think they're not doing what they're supposed to but yeh you have to kind of hold it back a bit until you know for sure because otherwise you are going to jump down their throats for doing the right thing.'

Similarly, Sam describes other strategies involving the interpretation of new gestures describing tapping on the iPad as 'a give-away' because:

'That's a game because yes what else would require you to tap like that other than a game...And then moving it (referring back to comment about tilting iPad)...And generally the kind of focus on the iPad. So if the person next to them is kind of interested....it can mean they're not doing something they're supposed to. Or if they've got it like that (demonstrates a stance of taking a sneaky photo of someone). And also of course you can see their notifications come up and you walk past them and they're being good...they're not touching them so they've got however many notification there.... waiting.'

What these insights into how Sam is creating the space for this new technology in the children's learning show, is how the technology brings new layers of complexity to the pedagogical process. These new layers of complexity need to be negotiated by the teacher and the learners in ways that allow the affordances of the tools to be exploited appropriately in ways that resonate with the educational goals identified. In negotiating these added complexities that the technology brings, Sam's prior experiences appear significant. For example her prior experiences; as someone able to take responsibility for her own learning with technology; as someone with experience 
and expertise in understanding the visual in the scientific; as someone who began her career working with SEN children trying to help them 'really understand'; as someone of several years teaching experience, all seem significant in enabling her to adapt her pedagogies remaining open to pedagogical adaptation yet sustaining a pragmatic approach.

\section{Conclusions}

The nature of this in-depth qualitative research limits the extent to which one can generalize from this case. However, it is appropriate to indicate how the evidence from this case fits with the general body of evidence emerging about mobile technology appropriation in education, which was discussed in detail in the earlier sections of this paper.

The evidence from Sam's case concurs with the literature discussed regarding the potential of mobile technologies to 'disrupt' established practices both at the micro and meso level. For example, at the micro level of classroom practice there was clear evidence of Sam adapting aspects of her practice in response to the introduction of the technology. A significant aspect of this concerned adjustments to her behaviour management strategies such as tolerating uncertainty regarding appropriate student behaviours with the iPads during lessons. This had also triggered Sam's development of a wider repertoire of behaviour cues to make sense of the various gestures involved in manipulating the technology, in order to gauge the extent to which students appeared to be on task. Also at the micro level of classroom practice, the introduction of the technology had prompted Sam to consider how to utilize the new opportunities offered by the technology but without losing the focus on the science subject content. Thus in working with the animation facilities, she had acted to limit the resources available to the students in order to ensure the scientific content was addressed. These examples represent specific ways in which the technology can 'disrupt' or challenge established professional practices at the micro level. However, similarly, at the meso level Sam faced the challenge of justifying to parents the use of the iPads in their children's education. From this perspective the introduction of the technology had the potential to 'disrupt' the important relationship between the wider community and the school and as such required Sam to act in order to counter the skepticism of parents and maintain their trust.

Using the narrative ecology model as a participatory tool to story the range of variable factors in Sam's case revealed a complex and rich picture highlighting the interdependency of a range of autobiographical and contextual factors involved in the appropriation of technologies in professional practice. Whilst the technological tool and its potential were significant, the exploitation of its educational value was mediated significantly by Sam's past experiences and current intentions. Her experience of her Human Sciences degree with its study of visual representation in science and her experience of working as a mentor to children with SEN gave another layer of nuance to her pedagogical adaptations in response to the introduction of the iPad. That is, the participatory approach to the use of the narrative ecology model 
helped to uncover tacit levels of critical reflection on Sam's part. Her ambiguity about limiting the children's resources when using the animation app were tempered by her pragmatic understanding of the need to address the scientific content and the level of visual literacy that would be required if the students were given more free rein. This level of critical reflection on practice - past experiences resonating with Sam's awareness of current limitations whilst remaining open to future potential - appeared to be laid bare through the use of a participatory narrative approach. These findings point to the need to place greater importance on making sense of the complex interdependency of factors at play when mobile technologies are appropriated into professional practice. Significantly, however, these findings are also indicative of the importance that educator and teacher perspectives can play in making sense of the complex ecology involved in pedagogical adaptation. From this perspective, the development of participatory methods would seem to be a priority for further research into this field.

Acknowledgements. The author would like to thank the Education Research Centre, School of Education, University of Brighton for the funding of this project. Thanks are also due to colleagues from the local partnership schools and the School of Education who took part in the mobile learning symposium and committed their time to participate in this project.

\section{References}

1. Turvey, K.: Narrative ecologies: Teachers as pedagogical toolmakers. Routledge, London (2013)

2. Pachler, N., Bachmair, B., Cook, J.: Mobile Learning: Structures, Agency, Practices. Springer, New York (2010)

3. Turvey, K.: Questioning the character and significance of convergence between social network and professional practices in teacher education. British Journal of Educational Technology 43(5), 739-753 (2012b)

4. Higher Education Funding Council England.: Enhancing learning and teaching through the use of technology: A revised approach to HEFCE's strategy for e-learning, London (2009)

5. JISC.: Effective Practice in a Digital Age, London (2009)

6. Jenkins, H.: Convergence culture: where old and new media collide. New York University Press, New York (2006)

7. Baron, N.S.: Always on: Language in an online and mobile world. Oxford University Press, Oxford (2008)

8. Pachler, N.: Research methods in mobile and informal learning: some issues. In: Vavoula, G., Pachler, N., Kukulska-Hulme, A. (eds.) Researching Mobile Learning: Frameworks, Tools and Research Designs. Peter Lang Publishing, Oxford (2009)

9. Traxler, J.: Defining, discussing, and evaluating mobile learning: The moving finger writes and having written. International Review of Research in Open and Distance Learning 8(2), $1-12(2007)$

10. Traxler, J.: Sustaining mobile learning and its institutions. International Journal of Mobile and Blended Learning 2(4), 58-65 (2010)

11. Crook, C.: The 'digital native' in context: Tensions associated with importing Web 2.0 practices into the school setting. Oxford Review of Education 38(1), 63-80 (2012) 
12. Castells, M., Fernandez-Ardevol, M., Linchuan Qiu, J., Sey, A.: Mobile Communication and Society: A Global Perspective. MIT Press, MA (2007)

13. Pachler, N., Ranieri, M., Manca, S., Cook, J.: Editorial: Social Networking and Mobile Learning. British Journal of Educational Technology 43(5), 707-710 (2012)

14. Selwyn, N.: Ten suggestions for improving academic research in education and technology. Learning, Media and Technology 37(3), 213-219 (2012)

15. Cuban, L.: Oversold and underused: Computers in the classroom. Harvard University Press, Cambridge (2001)

16. Laurillard, D.: Teaching as a Design Science: Building Pedagogical Patterns for Learning and Technology. Routledge, New York (2012)

17. Somekh, B.: Pedagogy and Learning with ICT: Researching the art of innovation. Routledge, New York (2007)

18. Pachler, N., Cook, J., Bachmair, B.: Appropriation of mobile cultural resources for learning. International Journal of Mobile and Blended Learning 2(1), 1-21 (2010)

19. Engeström, Y.: Learning by expanding: An activity-theoretical approach to developmental research. Orienta-Kosultit Oy, Helsinki (1987)

20. Engeström, Y.: Activity theory as a framework for analysing and redesigning work. Ergonomics 43(7), 960-974 (2000)

21. Engeström, Y.: Expansive Learning at Work: Toward an activity theoretical reconceptualisation. Journal of Education and Work 14(1), 133-156 (2001)

22. Nardi, B.: Studying context: A comparison of activity theory, situated action models, and distributed cognition. In: Nardi, B. (ed.) Context and Consciousness: Activity Theory and Human-Computer Interaction. MIT Press, Cambridge (1996)

23. Wertsch, J.V.: Mind as Action. Oxford University Press, New York (1998)

24. Ellis, V., Edwards, A., Smagorinsky, P. (eds.): Cultural-historical perspectives on teacher education and development: Learning Teaching. Routledge, Oxon (2010)

25. Goffman, E.: The Presentation of self in everyday life. Doubleday, New York (1959)

26. Perkins, D.N.: Person-plus: A distributed view of thinking and learning. In: Salomon, G. (ed.) Distributed Cognitions: Psychological and Educational Considerations. Cambridge University Press, Cambridge (1993)

27. Turvey, K., Pachler, N.: 'Problem spaces': A framework and questions for critical engagement with learning technologies in formal educational contexts. In: Rushby, N., Surry, D. (eds.) The Wiley Handbook of Learning Technology. Wiley-Blackwell (Forthcoming)

28. Turvey, K.: Constructing narrative ecologies as a site for teachers' professional learning with new technologies and media in primary education. E-Learning and Digital Media 9(1), 113-126 (2012a)

29. Fisher, T., Higgins, C., Loveless, A.: Teachers learning with digital technologies: A review of research and projects. Futurelab, Bristol (2006)

30. Loveless, A.: The interaction between primary teachers' perceptions of ICT and their pedagogy. Education and Information Technologies 8(4), 313-326 (2003)

31. Loveless, A.: Preparing to teach with ICT: Subject knowledge, Didaktik and Improvisation. Curriculum Journal 18(4), 509-522 (2007)

32. Klafki, W.: Didactic analysis as the core of preparation of instruction (Didaktische Analyse als Kern der Unterrichtsvorbereitung). Journal of Curriculum Studies 27(1), 13-30 (1958)

33. Selwyn, N., Facer, K.: The Politics of Education and Technology. Palgrave Macmillan, New York (2013)

34. Loveless, A., Williamson, B.: Learning Identities in a Digital Age: Rethinking Creativity, Education and Technology. Routledge, London (2013) 
35. Postman, N.: Technopoly: The surrender of culture to technology. Vintage Books, New York (1993)

36. Normak, P., Pata, K., Kaipainen, M.: An Ecological Approach to Learning Dynamics. Journal of Educational Technology \& Society 15(3), 262-274 (2012)

37. Goodson, I.F.: Investigating the teacher's life and work. Sense Publishers, Rotterdam (2008)

38. Schostak, J.: Interviewing and Representation in Qualitative Research. Oxford University Press, Maidenhead (2006)

39. Pata, K.: Participatory design experiment: Storytelling Swarm in hybrid narrative ecosystem. In: Daniel, B.K. (ed.) A Handbook of Research on Methods and Techniques for Studying Virtual Communities: Paradigms and Phenomena. Hershey, New York (2011)

40. Bruner, J.S.: Acts of Meaning. Harvard University Press, London (1990)

41. Crook, C., Harrison, C., Farrington-Flint, L., Tomas, C., Underwood, J.: The impact of technology: value-added classroom practice. Final report. BECTA, Coventry (2010), http: //dera.ioe.ac.uk/1771/ 